\title{
PENDAMPINGAN PENGEMBANGAN SOAL EKONOMI/AKUNTANSI BERBASIS ASESMEN KOMPETENSI MINIMUM (AKM) PADA GURU SMA ANGGOTA MGMP KABUPATEN JEMBER SEBAGAI PERSIAPAN ASESMEN NASIONAL PENGGANTI UN 2021
}

\author{
Sri Kantun ${ }^{1)}$, Tiara $^{1}$, Dwi Herlindawati ${ }^{1}$, Retna Ngesti Sedyati' ${ }^{1)}$, Anna Widayani²) \\ 1)Pendidikan EKonomi, FKIP, Universitas Jember, Jember, Jawa Timur, Indonesia \\ ${ }^{2)}$ Administrasi Server dan Jaringan Komputer, Akademi Komunitas Negeri Putra Sang Fajar Blitar, \\ Blitar, Jawa Timur, Indonesia \\ Corresponding author: Sri Kantun \\ E-mail : srikantun.fkip@unej.ac.id
}

Diterima 27 November 2021, Disetujui 02 Desember 2021

\begin{abstract}
ABSTRAK
Asesmen Kompetensi Minimum (AKM) merupakan asesmen yang mengukur kemampuan minimal yang dibutuhkan siswa untuk dapat belajar dan merupakan bentuk penyederhanaan dari Ujian Nasional yang begitu kompleks. Kegiatan ini dilakukan dengan tujuan memberikan pendampingan pengembangan soal ekonomi/akuntansi berbasis Asesmen Kompetensi Minimum (AKM) pada guru SMA anggota MGMP Kabupaten Jember sebagai persiapan asesmen nasional pengganti UN 2021. Metode yang digunakan dalam pengabdian masyarakat ini adalah metode Tutorial. Hasil yang didapat setelah dilakukannya kegiatan ini adalah peserta mampu menyusun soal-soal ekonomi/akuntansi berbasis Asesmen Kompetensi Minimum (AKM). Simpulan hasil pengabdian adalah guru SMA anggota MGMP dapat menambah pengetahuan tentang pembuatan soal berbasis AKM.
\end{abstract}

Kata kunci: pendampingan; soal berbasis AKM

\begin{abstract}
Minimum Competency Assessment (AKM) is an assessment that measures the minimum skills required by students to be able to learn and is a simplification of the complex National Examination. This activity was carried out to assist in the development of economic/accounting questions based on the Minimum Competency Assessment (AKM) for high school teachers who are members of the Jember Regency MGMP as a preparation for the national assessment to replace the $2021 \mathrm{UN}$. The method used in this community service is the Tutorial method. The results obtained after this activity was carried out were that participants were able to compile economic/accounting questions based on the Minimum Competency Assessment (AKM). The service results conclude that high school teachers who are members of MGMP can increase knowledge about making AKM-based questions.
\end{abstract}

Keywords: assistance; AKM-based questions.

\section{PENDAHULUAN}

Perkembangan teknologi informasi dan komunikasi (TIK) yang semakin pesat, mengakibatkan banyak terjadi perubahan di berbagai sektor, termasuk di bidang pendidikan. Bidang pendidikan saat ini mengalami perubahan yang cukup besar, mulai dari pembelajaran secara online sampai dengan ujian dengan sistem Computer based tes (CBT). Perubahan tidak hanya terkait dengan persiapan dan kemampuan guru dalam pembelajaran secara online, akan tetapi juga kemampuan guru dalam proses penilaian agar mampu mendiagnosis kemampuan siswa pada topik-topik penting yang menjadi skala prioritas. Selain itu, guru juga perlu menyesuaikan dengan pendekatan pembelajaran yang digunakan. Tujuan pendidikan adalah untuk mengembangkan potensi peserta didik agar kompeten, kreatif, mandiri dan berpikir kritis, sehingga perlu persiapan secara matang (Sari,dkk, 2021). Untuk mengetahui potensi yang dimiliki siswa maka perlu melakukan evaluasi pendidikan.

Evaluasi pendidikan merupakan salah satu komponen utama yang tidak terpisahkan dengan komponen pendidikan. Berdasarkan Undang-undang Nomor 20 Tahun 2003 Tentang Sistem Pendidikan Nasional menegaskan bahwa evaluasi pendidikan merupakan kegiatan pengendalian, penjaminan, dan penetapan mutu pendidikan terhadap berbagai komponen pendidikan pada setiap jalur, jenjang, dan jenis pendidikan sebagai 
bentuk pertanggungjawaban penyelenggaraan pendidikan. Dalam konteks pembelajaran evaluasi sangat penting baik bagi guru maupun siswa. Bagi guru evaluasi digunakan untuk mengetahui tercapainya tujuan pembelajaran, sedangkan bagi siswa untuk mengetahui kemampuan siswa dalam mengikuti proses pembelajaran.

Dari hasil belajar tersebut bisa sebagai tolak ukur terkait dengan keberhasilan pembelajaran. Hasil evaluasi yang telah dilakukan, maka guru dapat mengetahui sampai dimana kemampuan siswa dalam menguasai pelajaran, serta mengetahui kesulitan siswa dalam proses pembelajaran agar dapat dijadikan sebagai bahan perbaikan dan pengembangan program pembelajaran. Evaluasi tersebut dapat bermanfaat untuk menilai kemajuan pembelajaran jika mampu memberikan informasi yang dapat digunakan guru dan siswa sebagai umpan balik dalam menilai diri mereka sendiri dan satu sama lain dalam memodifikasi kegiatan belajar mengajar (Detlev,et al 2017).

Fenomena yang ada di lapangan, bahwa evaluasi pembelajaran masih bersifat pemahaman saja. Hal tersebut ditunjukkan dengan bentuk soal-soal yang sifatnya masih obyektif untuk mengukur kompetensi siswa yang tidak mengkaji secara mendalam tentang materi yang sudah dipelajari. Selama ini alat evaluasi hasil belajar akhir jenjang pendidikan di Indonesia tahun 2002-2003 merupakan ujian akhir nasional (UAN), yang kemudian pada tahun 2005 namanya menjadi ujian nasional (UN). Penerapan UN ternyata menuai berbagai polemik, pro kontra dan kontroversi yang senantiasa berlarut. Salah satu kenyataan yang menunjukkan hal itu adalah nilai UAN yang dianggap merugikan siswa-siswa yang pandai dan lebih menguntungkan siswa yang kurang pandai. Menurut (Fajri, 2015) Polemik ujian nasional yang berlangsung 18 tahun lamanya akhirnya selesai dengan kebijakan Kemdikbud yang dipublikasi pada tahun 2019 silam.

Ujian nasional yang selama ini digunakan tidak dapat mengukur pencapaian tujuan pendidikan yang telah ditentukan, karena setiap keberhasilan pendidikan akan dapat dilihat apabila alat evaluasi yang digunakan sesuai dan dapat mengukur kompetensi siswa. Alat evaluasi yang digunakan harus relevan agar hasil pengukuran tepat. Peraturan Menteri Pendidikan Dan Kebudayaan Republik Indonesia Nomor 43 Tahun 2019 tentang penyelenggaraan ujian yang diselenggarakan satuan pendidikan dan ujian nasional, salah satu poin yang terpenting dari dua kebijakan tersebut bahwa Ujian Nasional (UN) tahun 2020 merupakan UN terakhir yang akan diselenggarakan dalam sejarah pendidikan Indonesia. UN yang selama ini diselenggarakan di akhir jenjang sekolah dinilai merugikan siswa. Usaha siswa selama tiga tahun ditentukan oleh nasibnya pada saat mengikuti UN selama yang hanya berlangsung beberapa hari. Kegagalan siswa dalam menempuh UN tidak bisa ditempuh ulang. Hal tersebut tentunya sangat menekan kejiwaan siswa, karena merasa stress.

UN akan diperoleh hasil yang cepat karena proses ngoreksinya cepat dan mudah dengan menggunakan mesin scanner. Tetapi soal dalam UN bentuknya obyektif yang hanya mengukur proses pemahaman, ingatan, dan penerapan, tidak membiasakan siswa untuk berpikir tingkat tinggi. Seringkali siswa hanya menebak dalam memberikan jawaban, karena bahan pelajaran belum dipahami. Hasil dari UN dipandang oleh pemerintah tidak menghasilkan SDM sesuai dengan tuntutan kecakapan abad 21, dimana literasi merupakan salah satu kompetensi atau kemampuan yang harus dikuasai siswa, supaya mampu bersaing dengan dunia luar di era revolusi industry 4.0. Hal inilah yang mendorong pemerintah membuat kebijakan baru berupa penghapusan Ujian Nasional (UN) dan menggantinya menjadi Asesmen Kompetensi Minimum (AKM) mulai tahun 2021 mendatang. Sebagaimana yang telah disampaikan oleh Menteri Pendidikan dan Kebudayaan Nadiem Makarim pada tahun 2019, Asesmen Kompetensi Minimum (AKM) merupakan asesmen yang mengukur kemampuan minimal yang dibutuhkan siswa untuk dapat belajar dan merupakan bentuk penyederhanaan dari Ujian Nasional yang begitu kompleks (Albertus, 2020).

Asesmen Kemampuan Minimal (AKM) sebagai kebijakan baru dari Menteri Pendidikan dan kebudayaan, akan mengukur kemampuan literasi membaca dan numerasi, yaitu kemampuan bernalar menggunakan Bahasa (literasi membaca), dan kemampuan menghitung dengan mengaplikasikan konsep hitungan dalam sebuah konteks, baik abstrak ataupun nyata. (Mendikbud, 2020) Asesmen Kemampuan Minimal (AKM) merupakan penilaian kompetensi mendasar yang diperlukan oleh semua murid untuk mampu mengembangkan kapasitas diri dan berpartisipasi pasif pada masyarakat. Kompetensi mendasar yang diukur dalam AKM merupakan literasi numerasi/matematika dan literasi membaca. Adapun kompetensi yang nantinya akan dinilai mencakup beberapa keterampilan, antara lain keterampilan berpikir logis-sistematis, keterampilan bernalar dengan menggunakan konsep dan pengetahuan yang dipelajari, dan keterampilan memilah serta mengolah informasi. 
AKM menyajikan masalah yang disampaikan dengan berbagai konteks dengan harapan mampu diselesaikan oleh siswa dengan meenggunakan kompetensi numerisasi dan kompetensi literasi yang telah dimiliki oleh siswa. Hal ini memang dirancang untuk menghasilkan informasi yang memicu perbaikan kualitas belajar yang dapat meningkatkan hasil belajar siswa. Menurut (Sari dkk., 2021) Asesmen kompetensi minimum dan survei karakter ini juga diharapkan dapat memperbaiki kelemahan UN.

Pernyataan Menteri Pendidikan dan Kebudayaan tersebut tentang kebijakan menghapus UN dengan mengganti AKM tentu mendapatkan respon yang sangat bervariasi. Hal penghapusan UN menjadi masalah baru pada pendidikan khususnya bagi guru. Hal-hal yang dapat menjadi masalah tersebut, yaitu 1) adanya perspektif guru-guru yang berbeda, yakni pro ataupun kontra dengan penghapusan UN yang diganti menjadi asesmen kompetensi minimum dan survei karakter, 2) adanya ketidaksiapan guru dalam menjalankan kebijakan baru, dan 3) keraguan kualitas akan alat ukur AKM.

Persiapan yang dilakukan pemerintah dalam pemberlakuan AKM masih belum optimal. Hal tersebut ditunjukkan dengan minimnya informasi terkait AKM, karena belum adanya petunjuk teknis terkait kisi-kisi penyusunan soal AKM dan standar penilaian. Informasi tentang AKM masih sebatas waktu pelaksanaan. Hal tersebut membuat guru belum siap dan belum mengerti tentang AKM. Guru perlu mendalami terkait AKM dan mempersiapkan penyusunan soal-soal, kisi-kisi, dan standar penilaian berbasis AKM dengan kegiatan workshop. Permasalahn tersebut juga dihadapi oleh guruguru ekonomi/akuntansi MGMP kabupaten Jember.

\section{METODE}

\section{Langkah 1 (Metode Ceramah)}

Peserta diberikan gambaran umum tentang evaluasi pembelajaran yang dilakukan selama ini. Selain itu, peserta diberikan penjelasan tentang evaluasi pembelajaran yang dicanangkan pemerintah yaitu Assesmen Kompetensi Minimum (AKM) yang akan digunakan sebagai pengganti Ujian Nasional (UN). Langkah pertama akan dilaksanakan selama 5 jam secara online.

\section{Langkah 2 (Metode Tutorial)}

Peserta diberikan tutorial teknik membuat soal-soal Ekonomi/Akuntansi SMA yang berbasis Assesmen Kompetensi Minimum (AKM). Tutorial dilanjutkan dengan pendampingan tentang pembuatan soal-soal tersebut. Langkah ini dilakukan selama 3 hari secara Online.

\section{Langkah 3 (Metode Diskusi)}

Peserta diberikan kesempatan untuk mendiskusikan permasalahan yang berkaitan dengan pembuatan soal-soal Ekonomi/Akuntansi SMA yang berbasis Assesmen Kompetensi Minimum (AKM).

\section{Langkah 4 (Monitoring)}

Monitoring terhadap pembuatan pembuatan soal-soal Ekonomi/Akuntansi SMA yang berbasis Assesmen Kompetensi Minimum (AKM) dilakukan selama satu minggu.

Adapun target capaian luaran pelaksanaan pengabdian ini seperti yang terlihat pada Tabel 1 .

Tabel 1. Tarfget capaian luaran kegiatan pengabdian

\begin{tabular}{|c|c|c|}
\hline Tujuan & $\begin{array}{l}\text { Indikator } \\
\text { Ketercapaian }\end{array}$ & Tolak Ukur \\
\hline $\begin{array}{l}\text { Peserta } \\
\text { mengenal } \\
\text { assesmen } \\
\text { kompetensi } \\
\text { minimal } \\
\text { (AKM) } \\
\text { sebagai alat } \\
\text { ukur evaluasi }\end{array}$ & $\begin{array}{l}\text { Peserta mengenal } \\
\text { apa saja alat } \\
\text { evaluasi } \\
\text { pembelajaran } \\
\text { yang yang salah } \\
\text { satunya } \\
\text { assesmen } \\
\text { kompetensi } \\
\text { minimal (AKM) }\end{array}$ & $\begin{array}{l}\text { Peserta } \\
\text { mampu } \\
\text { menyebutkan }\end{array}$ \\
\hline $\begin{array}{l}\text { Peserta } \\
\text { mampu } \\
\text { membuat } \\
\text { soal-soal } \\
\text { ekonomi/aku } \\
\text { ntansi } \\
\text { berbasis } \\
\text { assesmen } \\
\text { kompetensi } \\
\text { minimal } \\
(\text { AKM) }\end{array}$ & 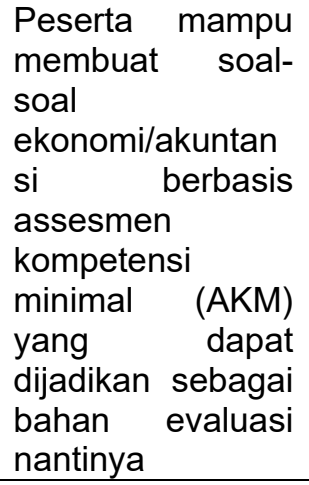 & $\begin{array}{l}\text { Peserta } \\
\text { memiliki } \\
\text { beberapa soal- } \\
\text { soal } \\
\text { ekonomi/akunt } \\
\text { ansi berbasis } \\
\text { assesmen } \\
\text { kompetensi } \\
\text { minimal (AKM) } \\
\text { yang dapat } \\
\text { digunakan } \\
\text { nantinya }\end{array}$ \\
\hline
\end{tabular}

\section{HASIL DAN PEMBAHASAN}

Berdasarkan hasil Pendampingan Pengembangan Soal Ekonomi/Akuntansi Berbasis Asesmen Kompetensi Minimum (AKM) Pada Guru SMA Anggota MGMP Kabupaten Jember Sebagai Persiapan Asesmen Nasional Pengganti UN 2021memberikan hasil sebagai berikut:

1. Kegiatan ini dilakukan secara daring.

2. Kegiatan pendampingan ini dilakukan untuk memberikan pengetahuan kepada Guru SMA Anggota MGMP Kabupaten Jember dalam pembuatan soal-soal Ekonomi/Akuntansi Berbasis Asesmen Kompetensi Minimum (AKM)

3. Pendampingan ini dilakukan secara bertahap kepada Guru SMA Anggota 
MGMP Kabupaten Jember antara lain sebagai berikut :

a. Pertama materi yang diberikan berupa pengetahuan tentang soal-soal berbasis AKM Pada saat pelaksanaan tersebut Guru SMA Anggota MGMP Kabupaten Jember antusias dalam mengikutinya.

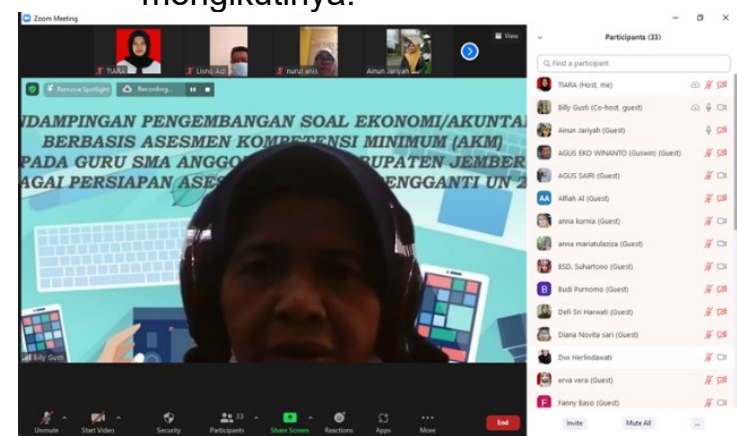

Gambar 1. Pemateri menyampaikan materi

b. Setelah selesai pemaparan yang disampaiakan oleh pemateri peserta melakukan latihan-latihan dalam pembuatan soal-soal berbasis AKM.

c. Kegiatan untuk pendampingan pembuatan soal-soal ini dilakukan beberapa kali selama 1 bulan. Sampai Guru SMA Anggota MGMP Kabupaten Jember memahami bagaimana cara membuat soal-soal AKM.

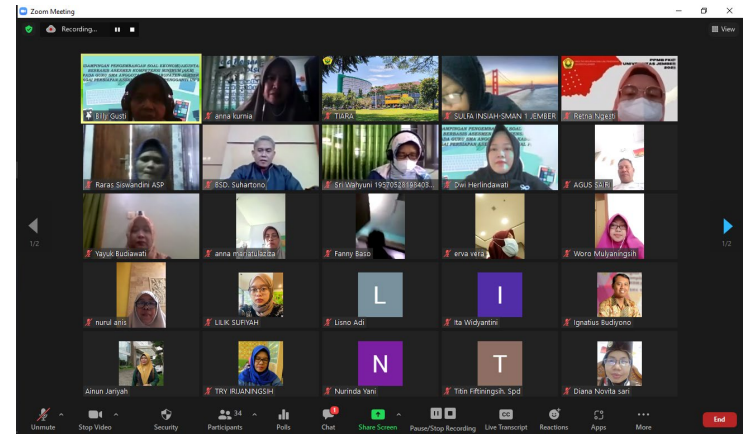

Gambar 2. Peserta antusias pada saat sesi tanya jawab

4. Berdasarkan hasil wawancara dari salah satu peserta pendampingan bahwa materi yang diberikan pada kegiatan pendampingan ini jelas, mudah diikuti dan sesuai dengan tujuan pelatihan dan berharap untuk ke depannya ada kegiatan lagi dalam bentuk peningkatan keterampilan.

\section{SIMPULAN DAN SARAN}

Kegiatan

Pendampingan Pengembangan Soal Ekonomi/Akuntansi Berbasis Asesmen Kompetensi Minimum (AKM) Pada Guru SMA Anggota MGMP Kabupaten Jember terlaksana dengan baik. Hal ini terbukti dengan antusias para peserta dalam
Volume 5, Nomor 1, Desember 2021.

p-ISSN : 2614-5251

e-ISSN : 2614-526X

mengikuti pelatihan dan langsung mempraktikan untuk membuat soal-soal Ekonomi/Akuntansi Berbasis Asesmen Kompetensi Minimum (AKM).

\section{Kendala}

Pelaksanaan kegiatan pengabdian kepada masyarakat yang dilakukan yaitu dengan memberikan pendampinan untuk pengembangan soal ekonomi/akuntansi berbasis asesmen kompetensi minimum (AKM) pada guru-guru SMA anggota MGMP Kabupaten Jember sebagai persiapan asesmen nasional pengganti UN. Kegiatan pendampingan dimaksudkan untuk meningkatkan kemampuan dan keteram[ilan guru dalam mengembangan soal ekonomi/akuntansi berbasis AKM yang memenuhi strandar. Materi yang disampaikan pada kegiatan pengabdian pada masyarakat meliputi:

1. guru-guru ekonomi/akuntansi memiliki keterampilan membuat soal berbasis AKM,

2. terlaksananya Asesmen Nasional pengganti UN 2021 untuk mata pelajaran ekonomi/akuntansi dengan baik, dan

3. perbaikan mutu pendidikan di lingkup sekolah.

Dari ketiga bahasan materi ini guruguru sangat antusias mengikuti pelatihan dan beberuapa guru mengajukan pertanyaan terkait soal-soal ekonomi/akuntansi berbasis AKM, namun tidak semua guru mendapat kesempatan untuk bertanya karena keterbatasan waktu pelatihan. Disamping itu karena pelaksanaan kegiatan dilakukan secara Daring maka seringkali hambatan terkait koneksitas jaringan tidak bisa dielakkan karena beberapa guru bertempat tinggal di tempat yang signalnya seringkali tidak stabil.

\section{UCAPAN TERIMAKASIH}

Penulis mengucapkan terima kasih kepada LPPM Universitas Jember.

\section{DAFTAR RUJUKAN}

Albertus. (2020). Penjelasannya, Apa Itu Asesmen Kompetensi Minimum? Retrieved from Kompas.com website: https://edukasi.kompas.com/read/2020 /10/26/162536471/apa-itu-asesmenkompetensi-minimum-simakpenjelasannya?page=all

Detlev Leutner, Jens Fleischer, Juliane Grunkorn, E. K. (2017). Competence Assessment in Education. https://doi.org/10.1007/978-3-31950030-0_16

Fajri Ismail. (2015). Pro Kontra Ujian Nasional. : : JUR Na LKE Pe N Di DiK a N, 7, 
http://ejournal.stain.sorong.ac.id/indeks .php/al-r.

Mendikbud. (2020). AKM dan Implikasinya pada Pembelajaran. Pusat Asesmen Dan Pembelajaran Badan Penelitian Dan Pengembangan Dan Perbukuan Kementerian Pendidikan Dan Kebudayaan, 1-37.

Peraturan Menteri Pendidikan Dan Kebudayaan Republik Indonesia Nomor 43 Tahun 2019. (n.d.). Penyelenggaraan Ujian Yang Diselenggarakan Satuan Pendidikan Dan Ujian Nasional. Lembaran Negara $R I, 53(9)$.

Sari, A., Daulay, S., Putri, Y. Y., Epriani, P., \& Medan, U. N. (2021). Penghapusan Ujian Nasional Tahun 2021 Dalam Perspektif. 213-220.

Undang-undang Nomor 20 Tahun 2003. (n.d.). Sistem Pendidikan Nasional. 18, 1928. 